\title{
Differences in the Reaction of North Equatorial Countercurrent to the Developing and Mature Phase of ENSO Events in the Western Pacific Ocean
}

\author{
Yusuf Jati Wijaya ${ }^{1,2}$ and Yukiharu Hisaki ${ }^{1, *(D)}$ \\ 1 Department of Physics and Earth Sciences, University of the Ryukyus, Senbaru 1, Nishihara-cho, \\ Okinawa 903-0213, Japan; yusufjatiwijaya@gmail.com \\ 2 Department of Oceanography, Faculty of Fisheries and Marine Science, Diponegoro University, Semarang, \\ Jawa Tengah 50275, Indonesia \\ * Correspondence: hisaki@sci.u-ryukyu.ac.jp; Tel.: +81-98-895-8515
}

check for updates

Citation: Wijaya, Y.J.; Hisaki, Y. Differences in the Reaction of North Equatorial Countercurrent to the Developing and Mature Phase of ENSO Events in the Western Pacific Ocean. Climate 2021, 9, 57. https://doi.org/10.3390/cli9040057

Academic Editors: Maria

Teresa Caccamo and

Salvatore Magazù

Received: 3 March 2021

Accepted: 2 April 2021

Published: 5 April 2021

Publisher's Note: MDPI stays neutral with regard to jurisdictional claims in published maps and institutional affiliations.

Copyright: (c) 2021 by the authors. Licensee MDPI, Basel, Switzerland. This article is an open access article distributed under the terms and conditions of the Creative Commons Attribution (CC BY) license (https:// creativecommons.org/licenses/by/ $4.0 /)$.

\begin{abstract}
The North Equatorial Countercurrent (NECC) is an eastward zonal current closely related to an El Niño Southern Oscillation (ENSO) event. This paper investigated the variations of NECC in the Western Pacific Ocean over 25 years (1993-2017) using satellite data provided by the Copernicus Marine Environment Monitoring Service (CMEMS) and the Remote Sensing System (RSS). The first mode of empirical orthogonal function (EOF) analysis showed that the NECC strengthened or weakened in each El Niño (La Niña) event during the developing or mature phase, respectively. We also found that the NECC shifting was strongly coincidental with an ENSO event. During the developing phase of an El Niño (La Niña) event, the NECC shifted southward (northward), and afterward, when it entered the mature phase, the NECC tended to shift slightly northward (southward). Moreover, the NECC strength was found to have undergone a weakening during the 2008-2017 period.
\end{abstract}

Keywords: North Equatorial Countercurrent (NECC); Western Pacific Ocean; ENSO; developing phase; mature phase

\section{Introduction}

Along with the North Equatorial Current (NEC), the North Equatorial Countercurrent (NECC) is one of the significant features that establishes the low-latitude North Pacific Gyre. The NECC is an eastward flow between $2^{\circ}$ and $6^{\circ} \mathrm{N}$ across the Pacific Ocean Basin [1]. As it flows eastward, the NECC shifts to $7^{\circ} \mathrm{N}$ in the Central Pacific and becomes deeper in the east [2-4]. Lying near the Equatorial Pacific Ocean, the NECC has an important role in the eastward propagation of warm water. On average, the NECC carries 18-24 Sv of water to the Eastern Pacific Ocean [5,6]. Numerous studies have examined the seasonal, interannual, and interdecadal variation of NECC using satellite information, numerical approaches, and in situ data observations [1-7].

In the Western Pacific Ocean, the path of the NECC is strongly associated with the appearance of the Mindanao Eddy situated around $7^{\circ} \mathrm{N}$ and $130^{\circ} \mathrm{E}$, and the Halmahera Eddy, located around $4^{\circ} \mathrm{N}$ and $135^{\circ}$ E. The differences in sea surface height (SSH) between such above eddy regions affect the magnitude of the NECC [7-9]. The seasonal shifting of the NECC's path in the Western Pacific Ocean has been reported in several studies, in which the NECC shifts northward from January to March and southward in late summer [6,7]. Employing multi-satellite products and numerical models, the NECC's response to the El Niño Southern Oscillation (ENSO) was investigated in [1,5], in which the NECC path shifted equatorially during an El Niño event. Several prior studies have divided El Niño into two types, based on the distribution of the sea surface temperature anomaly (SSTA), (i.e., the Eastern Pacific (EP) and the Central Pacific (CP)), and found differences in the NECC's response to them [8-12]. Tan and Zhou [12] found that the 
NECC shifted southward and was stronger in the Western Pacific Ocean during a CP El Niño event, while this did not happen during an EP El Niño event. After a long break, an extreme El Niño occurred in 2015/2016, the first (extreme one) since 1997/1998. The extreme El Niño events showed differences in their development; the 1997/1998 event was categorized as an EP El Niño, whereas the 2015/2016 event was a mixture of both CP and EP El Niño events [13,14].

Several prior studies have focused on an ENSO event's impact on NECC variations over certain years; however, they did not consider the differences between the developing and mature phases. Thus, the main purpose of this study was to investigate the variations in the NECC during the developing and mature phases of ENSO events over a 25-year period. Previous studies have reported that the developing and mature phases of ENSO events occur mostly in boreal summer and winter, respectively $[15,16]$. To achieve the aims of the study, we used the latest satellite altimetry data. The remaining sections of the article are as follows: Section 2 contains an explanation of the data and the methods used; Section 3 contains the study results, followed by the discussion and conclusions in the final section.

\section{Materials and Methods}

In this paper, our data came from the Copernicus Marine Environment Monitoring Service (CMEMS), consisting of daily data on the SSH and the surface geostrophic velocity under the code number 008_047 and processing level 4 (L4), extended from $0.875^{\circ} \mathrm{S}$ $17.875^{\circ} \mathrm{N}$ and $119.875^{\circ} \mathrm{E}-180.125^{\circ} \mathrm{E}$ on a $0.25^{\circ} \times 0.25^{\circ}$ longitude-latitude grid. The data were generated by a combination of several satellite altimetry missions (JASON-1 and 2, ENVISAT and ERS-1 and 2). We extracted anomaly data on SSH over 25 (1993-2017) years as an indicator for observations.

Geostrophic velocity from satellite altimetry was obtained from the first derivative of the SSH data. The zonal $(u)$ and meridional $(v)$ components of geostrophic velocity can be derived from Equation (1), as follows:

$$
u_{s}=-\frac{g}{f} \frac{\partial \eta}{\partial y}, v_{s}=\frac{g}{f} \frac{\partial \eta}{\partial x}
$$

where $g$ is the gravitational constant; the Coriolis parameter, $f$ is calculated using the equation $f=2 \Omega \sin \varphi$, where $\Omega$ is the angular speed of the earth rotation and $\varphi$ is the latitude; $\eta$ is the SSH obtained from the altimeter data [17].

The above calculations are a common form of geostrophic velocity that cannot be applied near the equator because the Coriolis parameter is almost 0 . Therefore, the formula used was the derivative of the geostrophic component (Equation (2)) in an equatorial $\beta$-plane approximation $(f=\beta y)[18]$, so the expression was as in Equation (3):

$$
\begin{gathered}
\text { if } U_{g}=-g Z \\
\beta U_{\beta}+\beta y \frac{\partial U_{\beta}}{\partial y}=i g \frac{\partial Z}{\partial y}
\end{gathered}
$$

where $U_{g}=u_{g}+i v_{g}, Z=\frac{\delta \eta}{\delta y}+i \frac{\delta \eta}{\delta x}$, and $U_{\beta}=u_{\beta}+i v_{\beta}$ near the equator. Polynomial expansion with respect to latitude was then applied to approximate the solution of Equation (3). Subsequently, the geostrophic current near the equator was obtained by weighting $U_{s}$ and $U_{\beta}$ :

$$
\left(u_{g}, v_{g}\right)=W_{\beta}\left(u_{\beta}, v_{\beta}\right)+W_{s}\left(u_{s}, v_{s}\right)
$$

where $W_{\beta}=1$ and $W_{s}=0$ at the equator, while $W_{\beta} \rightarrow 1$ and $W_{s} \rightarrow 0$ as the latitude increases (at $5^{\circ} \mathrm{N}$ and $5^{\circ} \mathrm{S}$ ). This formula has been described in more detail in previous studies [18,19].

Suzuki et al. [20] compared several sources of wind speed datasets and found that the Cross-Calibrated Multi-Platforms (CCMP) dataset was the most accurate. Therefore, CCMP 
V2 data provided by the Remote Sensing System (RSS) were employed to describe wind patterns at the time of observation, with a $0.25^{\circ} \times 0.25^{\circ}$ spatial resolution and six-hourly time interval. Detailed specification, data assimilation methods, and other information on the CCMP data can be found in the studies by Atlas et al. [21] and Mears et al. [22]. We converted the wind stress curl from wind data using Equation (5):

$$
W S C=\frac{\partial \tau_{y}}{\partial x}-\frac{\partial \tau_{x}}{\partial y}
$$

where $\tau_{y}$ and $\tau_{x}$ are the wind stress components that were obtained using Equations (6) and (7) from Kok et al. [23] and Kutsuwada [24]:

$$
\begin{aligned}
& \tau_{x}=\rho_{a} C_{d}\left(u^{2}+v^{2}\right)^{1 / 2} u \\
& \tau_{y}=\rho_{a} C_{d}\left(u^{2}+v^{2}\right)^{1 / 2} v
\end{aligned}
$$

where $\rho_{a}$ is the density of air that equaled $1.2 \mathrm{~kg} / \mathrm{m}^{3}, C_{d}$ is the value of the drag coefficient $\left(1.3 \times 10^{-3}\right)$, while $u$ and $v$ are the zonal and meridional components of wind speed, respectively.

Wind data sets were also used to calculate the Sverdrup balance to investigate the relationship between the NECC and local wind stress more deeply. As described by Kessler et al. [25], the Sverdrup zonal transport was calculated as follows:

$$
U=-\frac{1}{\beta} \int W S C d x
$$

We also used sea surface temperature (SST) data in the Niño 3.4 region $\left(5^{\circ} \mathrm{S}-5^{\circ} \mathrm{N}\right.$ and $170^{\circ} \mathrm{W}-120^{\circ} \mathrm{W}$ ) of optimal interpolation sea surface temperature (OISST) products from National Oceanic and Atmospheric Administration (NOAA), which were used to determine the cross-correlation between the NECC and ENSO. The datasets downloaded from the Asia-Pacific Data-Research Center (APDRC) had a spatial resolution of $0.25^{\circ} \times 0.25^{\circ}$ from January 1993 to December 2017. See Reynold et al. [26] for more detailed information and explanation about the data quality.

Because we employed data that covered a wide area and period of time, we utilized an empirical orthogonal function (EOF) approach commonly used for massive data processing in climatology and oceanography. EOF analysis for atmospheric science has been well described and applied in previous studies [27-29]. To produce two dominant NECC variations during the developing and mature phases of an ENSO event, we calculated the first three EOF boreal summers (JJA) and winters (DJF) over the 25 years. Moreover, to obtain the correlation coefficient, Pearson correlations and $t$-tests were used. The effective degrees of freedom were estimated using Equation (9), taken from Chelton [30]:

$$
N^{*}=\frac{N}{\left(\sum_{\tau=-\infty}^{\infty} \rho_{x x}(\tau) \rho_{y y}(\tau)+\rho_{x y}(\tau) \rho_{y x}(\tau)\right)}
$$

where $N$ is the number of data, $N^{*} \leq N, \rho_{y y}(\tau)$ is the autocovariance of the output, $\rho_{x x}(\tau)$ is the autocovariance of the input, while $\rho_{x y}(\tau)$ and $\rho_{y x}(\tau)$ are the cross-covariances between the input and output.

\section{Results}

\subsection{Variations of the NECC}

To investigate NECC variations, we defined the meridional line at $137.125^{\circ} \mathrm{E}$ as a reference to facilitate the observation. We assumed that the NECC frequently crossed the reference line, as shown in Figure 1, and that the NECC was closely related to the ENSO event at that point, as shown in Figure 2. 


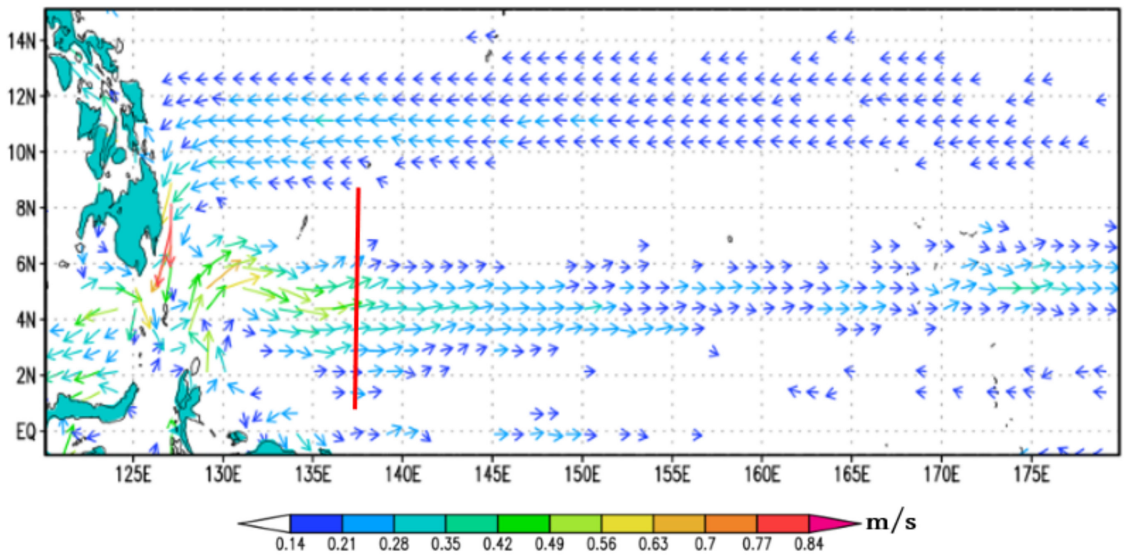

Figure 1. Mean surface geostrophic velocity from satellite altimetry of January 1993 to December 2017. The red line indicates the meridional line at $137.125^{\circ} \mathrm{E}$.

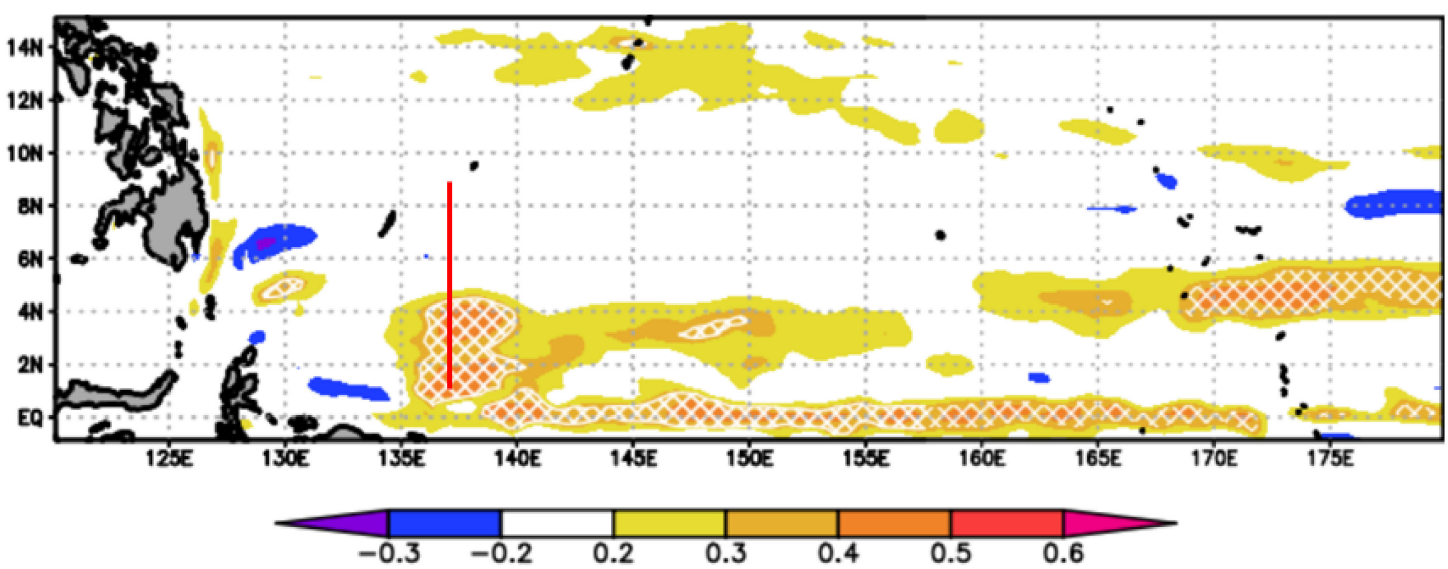

Figure 2. Cross-correlation map of the geostrophic surface current magnitude $\left(\sqrt{u^{2}+v^{2}}\right)$ and sea surface temperature anomaly (SSTA) at the Niño 3.4 region with no temporal lag. Shaded white tiles denote statistical significance above the $95 \%$ confidence level. The red line indicates the meridional line at $137.125^{\circ} \mathrm{E}$.

To identify the influence of ENSO events in the Western Pacific Ocean, we applied time series data on the surface geostrophic velocity and SSTAs at the Niño 3.4 region to generate a correlation map, shown in Figure 2. An area of positive correlation covered the NECC region, which extended from $135^{\circ}$ to $155^{\circ} \mathrm{E}$ with $\mathrm{r}>0.3$, while the highest statistically significant correlation $(r>0.5)$ was found near longitude $137^{\circ}$ E. Moreover, there was a highly positive correlation elongated in the equatorial region. Another positive correlation was seen in the NEC region, although the correlation was not significant.

To investigate the NECC variations over 25 years, we plotted surface geostrophic current as a function of latitude and time (Figure 3). The maximum speed was considered for the plot in Figure 3, showing variations in the NECC's path. The NECC in this region tended to shift southward and northward when El Niño and La Niña occurred, respectively. Using criterion of $+/-0.5$ as the threshold for El Niño and La Niña events, El Niño events were recorded in the year 1994/1995, 1997/1998, 2002/2003, 2004/2005, 2006/2007, $2009 / 2010,2014 / 2015$, and 2015/2016. While there were 10 La Niña events in the record, namely, in 1995/1996, 1998/1999, 1999/2000, 2000/2001, 2005/2006, 2007/2008, 2008/2009, 2010/2011, 2011/2012, and 2016/2017. In terms of magnitude, the NECC tended to be stronger during El Niño and weaker during La Niña events. However, it should be noted that the strengthened of NECC in El Niño was more noticeable than weakened of NECC in La Niña. When extreme El Niño events occurred in 1997/1998 and 2015/2016, the NECC became immensely strong, then significantly weakened in the following event, followed by a drastic decline in the Niño 3.4 index. 


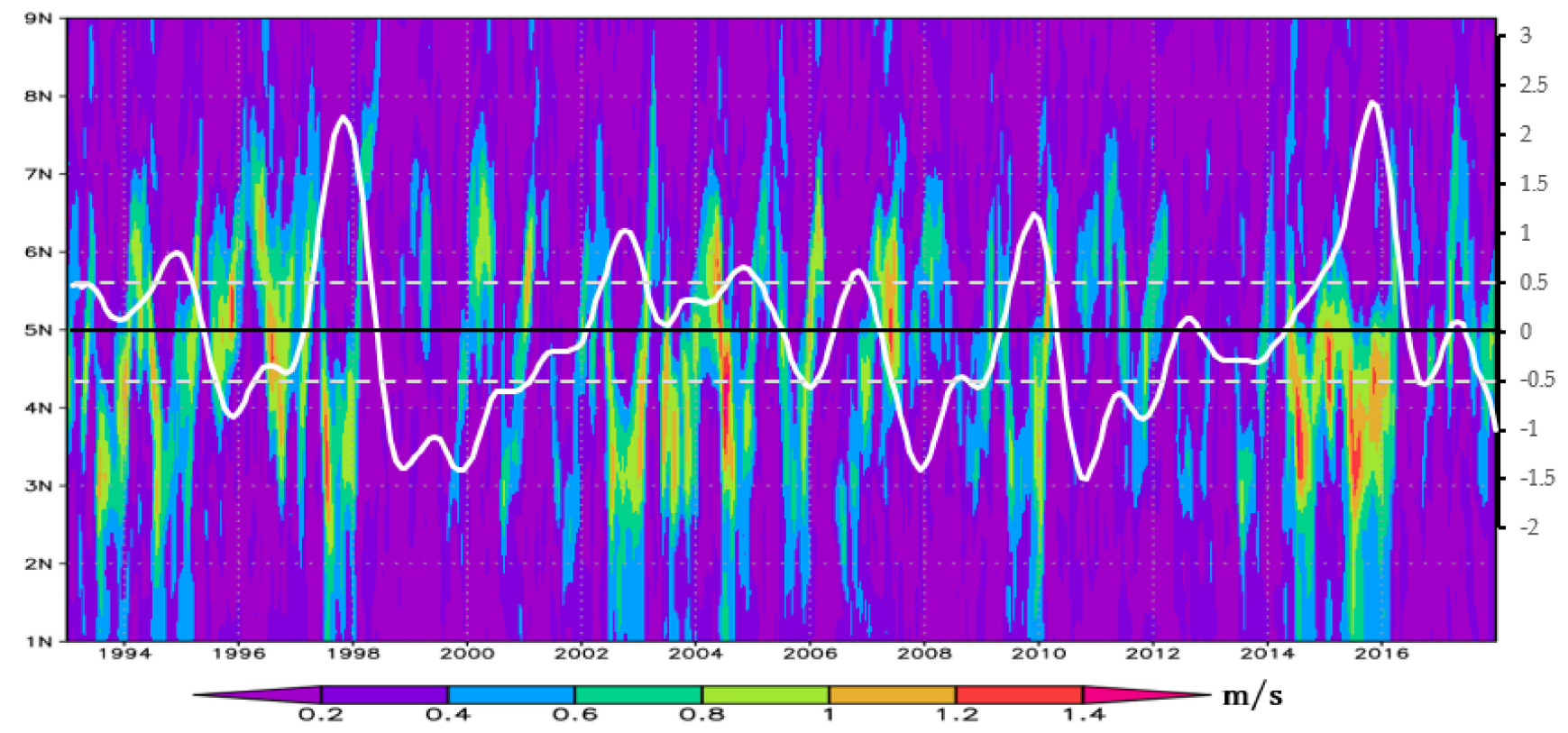

Figure 3. Latitude-time diagram of 90 days of low-pass filtered North Equatorial Countercurrent (NECC) variability (m/s) from satellite altimetry data from 1993-2017 at the meridional line of $137.125^{\circ}$ E, superimposed over six months of low-pass filtered Niño 3.4 index data (white line). Latitude and time are indicated by the $x$ - and $y$-axes, respectively.

However, in the present study, we intended to obtain more information about the NECC variations over the 25 years. Therefore, we extracted the surface geostrophic velocity and calculated the first three EOFs over the Western Pacific Ocean for JJA and DJF to identify the NECC's dominant modes during boreal summer and winter, respectively.

In Figure 4, plots are shown for the EOF analysis expressing the two dominant modes of geostrophic current in the Western Pacific Ocean for boreal summer (JJA). The first mode accounted for $36.1 \%$ of the variance; the spatial pattern of this mode showed positive values that extended into the NECC region starting from near $135^{\circ} \mathrm{E}$, with negative values for the northern part (near $6^{\circ} \mathrm{N}$ ). In this mode, it was also very clear that the NECC lay near the equator, and the magnitude appeared to be stronger. The time-series variation from the first mode in the plot depicts a strengthening of the NECC, which corresponded with El Niño developing years, unless there was an exceptional 2009/2010 El Niño event, in which case the NECC appeared in a neutral phase.

On the contrary, the second leading mode explained $11.4 \%$ of the variance. The spatial pattern was dominated by positive values in the north, while negative values were observed in the southern part. In this mode, the NECC tended to shift northward and was weaker than the first mode. From the second mode in the plot, the relationship to the ENSO event seemed to be weak. However, the second mode in the plot showed a negative phase during the 2008-2017 period. 

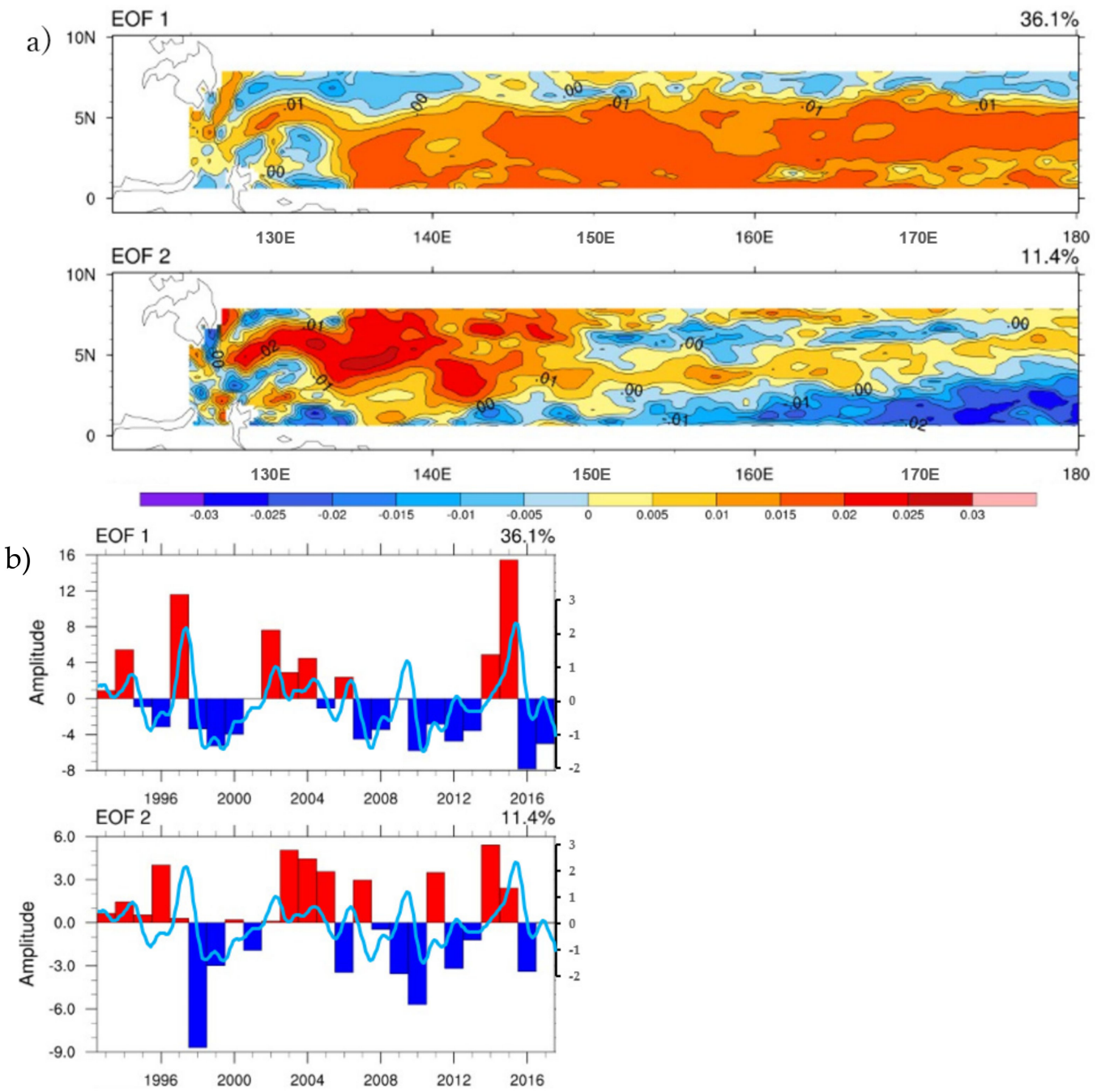

Figure 4. Empirical orthogonal function (EOF) analysis of the geostrophic current magnitude for boreal summer (JJA): (a) Spatial pattern and (b) Principal Component (PC) bar graph superimposed with six months of low-pass filtered Niño 3.4 index data.

A turn to the dominant modes of geostrophic current was seen for boreal winter (Figure 5). The spatial pattern was dominated by positive values, which accounted for $26.3 \%$ of the variance; the largest positive value was found to extend from $130^{\circ} \mathrm{E}$ to $140^{\circ} \mathrm{E}$. This result implies that the NECC was greatly dominated by eddy occurrence. As we already know, there was Halmahera eddy activity near that region. Furthermore, the NECC tended to shift northward and was weaker than the boreal summer EOF (Figure 4). While the temporal series in the plot indicated a strong relationship with the ENSO events in each El Niño and La Niña year, it was repeatedly accompanied by positive and negative phases. The highest phase was seen during the El Niño event in 2015/2016, while the lowest phase detected was in La Niña event (2007/2008). 
a)
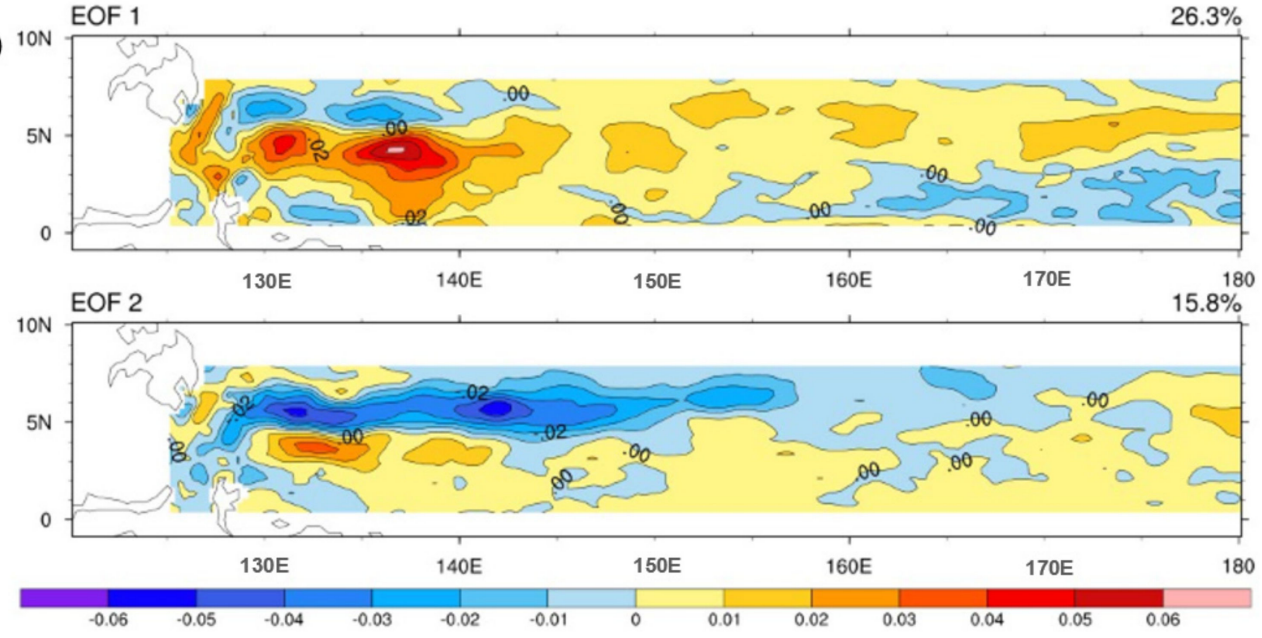

b)
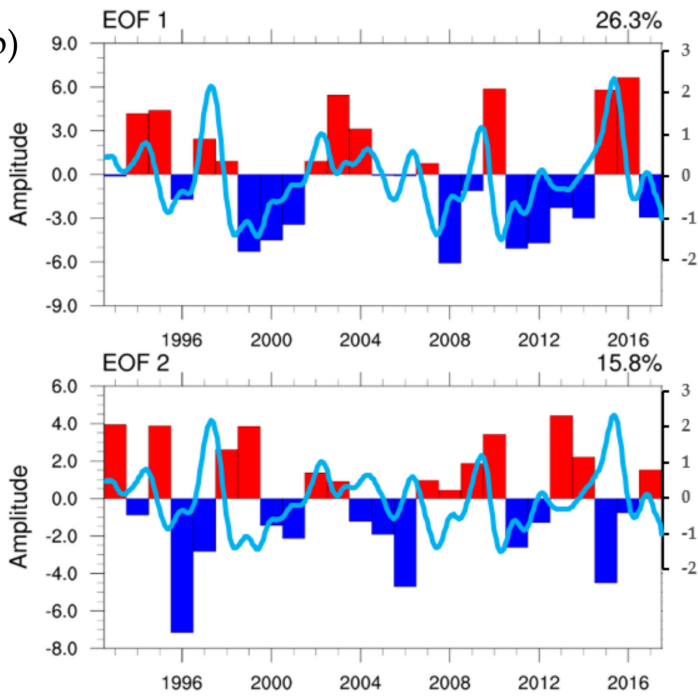

Figure 5. EOF analysis of the geostrophic current magnitude for boreal winter (DJF): (a) Spatial pattern and (b) PC bar graph superimposed with six months of low-pass filtered Niño 3.4 index data.

The second mode accounted for $15.8 \%$ of the variance, as negative values covered the area near latitude $5^{\circ} \mathrm{N}$ and elongated eastward (Figure 5). Moreover, the positive values were seen near latitude $6^{\circ} \mathrm{N}$. This mode implies that the NECC seemed to be shifting southward toward the equator. Compared to the first mode, the time series in the plot showed a less intense relationship with ENSO events. However, the time series in the plot still captured the lowest phase in the La Niña event of 1995/1996.

We also investigated the lead-lag correlations of the Niño 3.4 and the NECC by employing daily data (Figure 6). The NECC showed a remarkable correlation with SSTA in the Niño 3.4 region (Figure 6). This result indicates that the NECC was ahead of the ENSO event by 2-4 months of lag time, suggesting that the ENSO event had a strong relationship with the NECC variations during the developing phase. This result is consistent with previous studies that found obvious change in NECC strength and position during that phase [5,7]. Furthermore, the maximum correlation coefficient between the SSTA in the Niño 3.4 region and the NECC was $r>0.6$, indicating that the strengthening and weakening of the NECC in the Western Pacific Ocean occurred during El Niño and La Niña events, respectively. However, the present result also implies the other possibility that the NECC causes ENSO events. Therefore, observations by involving other components will be examined in the next subsections and then this point is also discussed in the last section. 


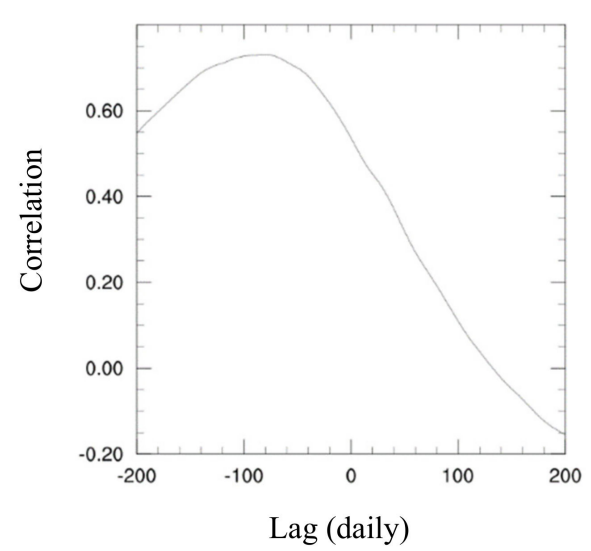

Figure 6. Lead-lag correlation between the SSTA at the Niño 3.4 region and the average NECC $\left(1.125^{\circ} \mathrm{N}\right.$ to $7.125^{\circ} \mathrm{N}$ and $135.125^{\circ} \mathrm{E}$ to $\left.170.125^{\circ} \mathrm{E}\right)$. Negative lag indicates that the SSTA was lagging, and positive lag indicates that the SSTA was leading.

\subsection{Wind Forcing}

The surface ocean current is strongly determined and dominated by wind pattern distributions, as has been proposed for developing simulation models in previous NECC investigations [31,32]. Therefore, we plotted the average of the zonal component anomalies of wind stress extracted from wind data from 1993 to 2017 (Figure 7). It can be seen that in several boreal summers and the early fall of El Niño events, a strengthening of westerly wind in the Western Pacific Ocean was observed. This occurred in the strong and moderate events of El Niño, namely, in 1994/1995, 1997/1998, 2002/2003, and 2015/2016. The strongest and weakest westerly winds were observed during the boreal summer of 2015 El Niño and 2010 La Niña (Figure 7). Thus, this result supports the relationship between westerly wind and an ENSO event, as stated in previous studies [33-35]. Furthermore, McPhaden et al. [36] found that a strengthening of the westerly wind resulted in an increase in eastward volume transport in the Western Pacific Ocean.

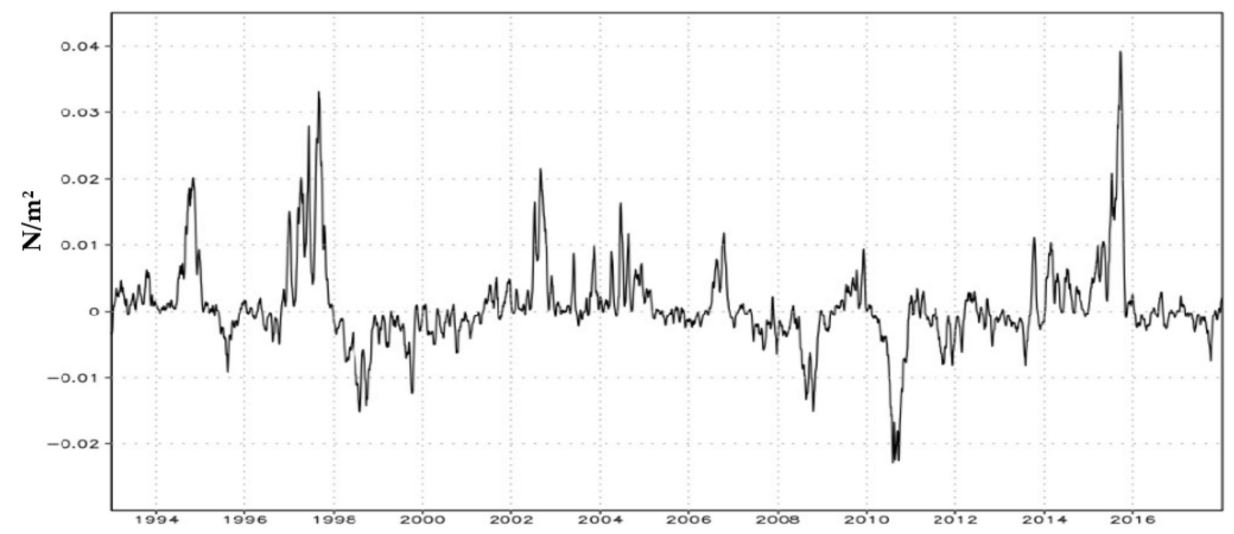

Figure 7. Average of the zonal component anomaly of wind stress $\left(\mathrm{N} / \mathrm{m}^{2}\right)$ in the Western Pacific Ocean $\left(125.125^{\circ} \mathrm{E}\right.$ to $180.125^{\circ} \mathrm{E}$ and $0.125^{\circ} \mathrm{N}$ to $\left.14.125^{\circ} \mathrm{N}\right)$.

Furthermore, we assessed wind stress curl (WSC) along the Pacific Ocean (Figure 8) to investigate the influence of wind forcing on the NECC in the Western Pacific Ocean, especially during El Niño and La Niña events. To perceive the difference in WSC patterns during both events, we looked at two years of both El Niño and La Niña events that fell into the strong category, and the differences were quite clear. In the El Niño events of 1997/1998 and 2015/2016, the WSC was positive and dominated in the Western Pacific Ocean; it started to emerge in the earlier event and moved toward the Central Pacific Ocean. The WSC seemed to be more massive and steady during the 1997/1998 event than in the 2015/2016 event, in good agreement with Wang and Wu [11], who found that the WSC 
was larger in the EP El Niño event than in the CP El Niño event, as mentioned in Section 1. During the La Niña 2010/2011 and 2009/2010 events, the WSC was dominated by negative values that frequently appeared in the Western Pacific Ocean. Zhao et al. [7] found that positive and negative wind stress stimulated upwelling and downwelling during El Niño and La Niña events, respectively. Chen et al. [5] noted a reduction in WSC intensity, which corresponded with the weakening of the NECC speed. A lead-lag correlation analysis between WSC in the Niño 3.4 region and the NECC in the Western Pacific Ocean was shown in Appendix A Figure A1. In the observations, the largest correlation (0.42) occurred when the NECC led the WSC by 2-4 months lag time. The shape of this curve was similar to Figure 6 (2-4 months lag was the same), but correlation was lower because WSC was noisier.

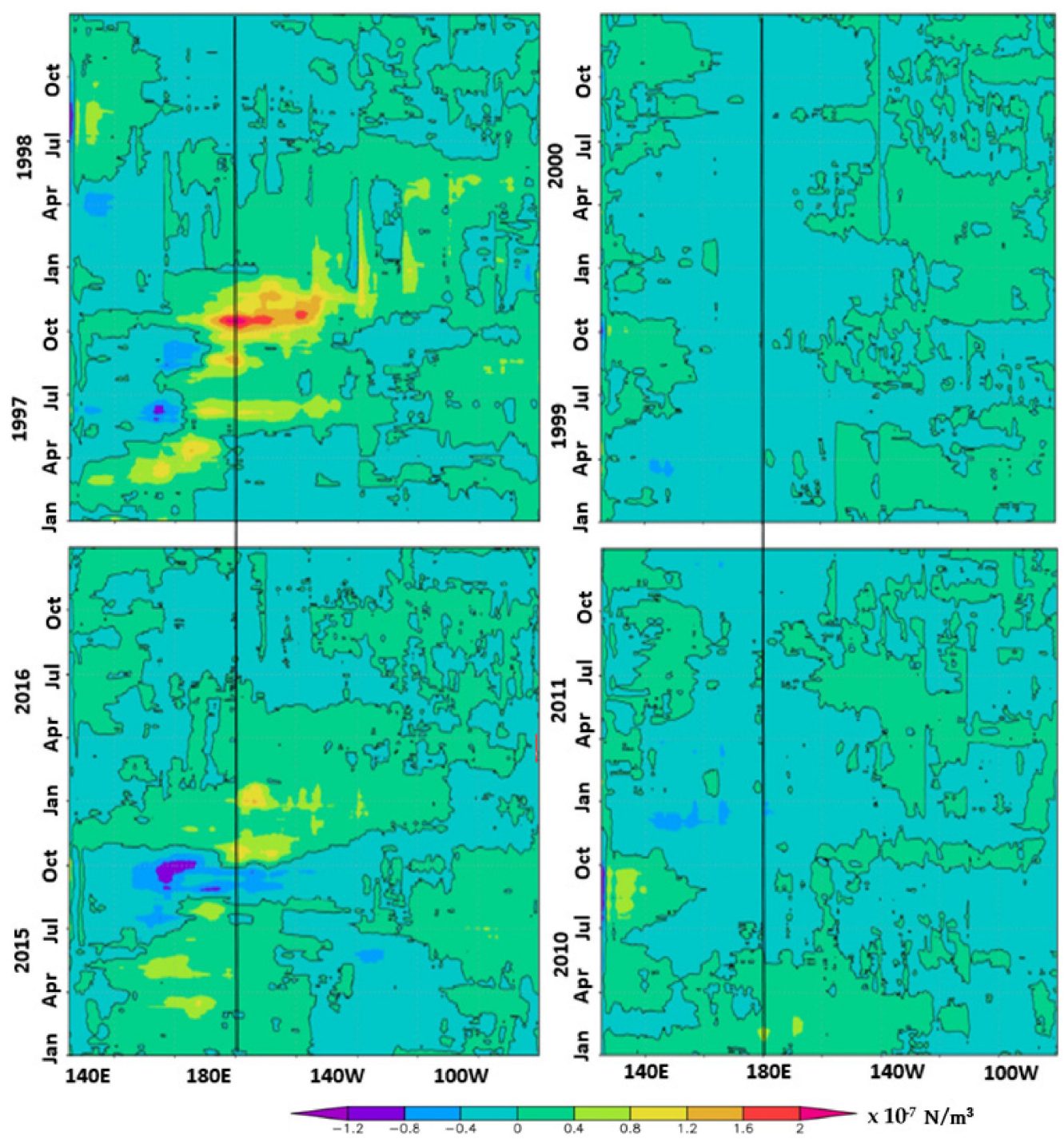

Figure 8. Hovmoller diagrams of wind stress curl $\left(\mathrm{N} / \mathrm{m}^{3}\right)$ with 35 days of low-pass filtered data averaged within $1^{\circ} \mathrm{N}-7^{\circ} \mathrm{N}$. Left panel: El Niño event; right panel: La Niña event. The black line is the boundary of the observation area.

To investigate the relationship between NECC and WSC variations, we performed analyses based on the Sverdrup balance relationship. Employing the $0.25^{\circ} \times 0.25^{\circ}$, daily WSC data, we compared the Sverdrup balance (SB) during the developing and mature phases of an ENSO event (Figure 9). We used the average of SB that occurred during El Niño and La Niña events. Comparing two ENSO events, a significant difference was found. The WSC produced an eastward transport near the equator in the developing 
phase of an El Niño event and shifted to the north of $\sim 8^{\circ} \mathrm{N}$ during the mature phase (Figure 9d). The opposite condition happened in the La Niña events; the eastward transport was located at $\sim 7^{\circ} \mathrm{N}$ during the developing phase and shifted south of $\sim 1^{\circ} \mathrm{N}$ during the mature phase. The shift of eastward transport from the SB analysis is in agreement with the NECC variations seen in the EOF analysis.
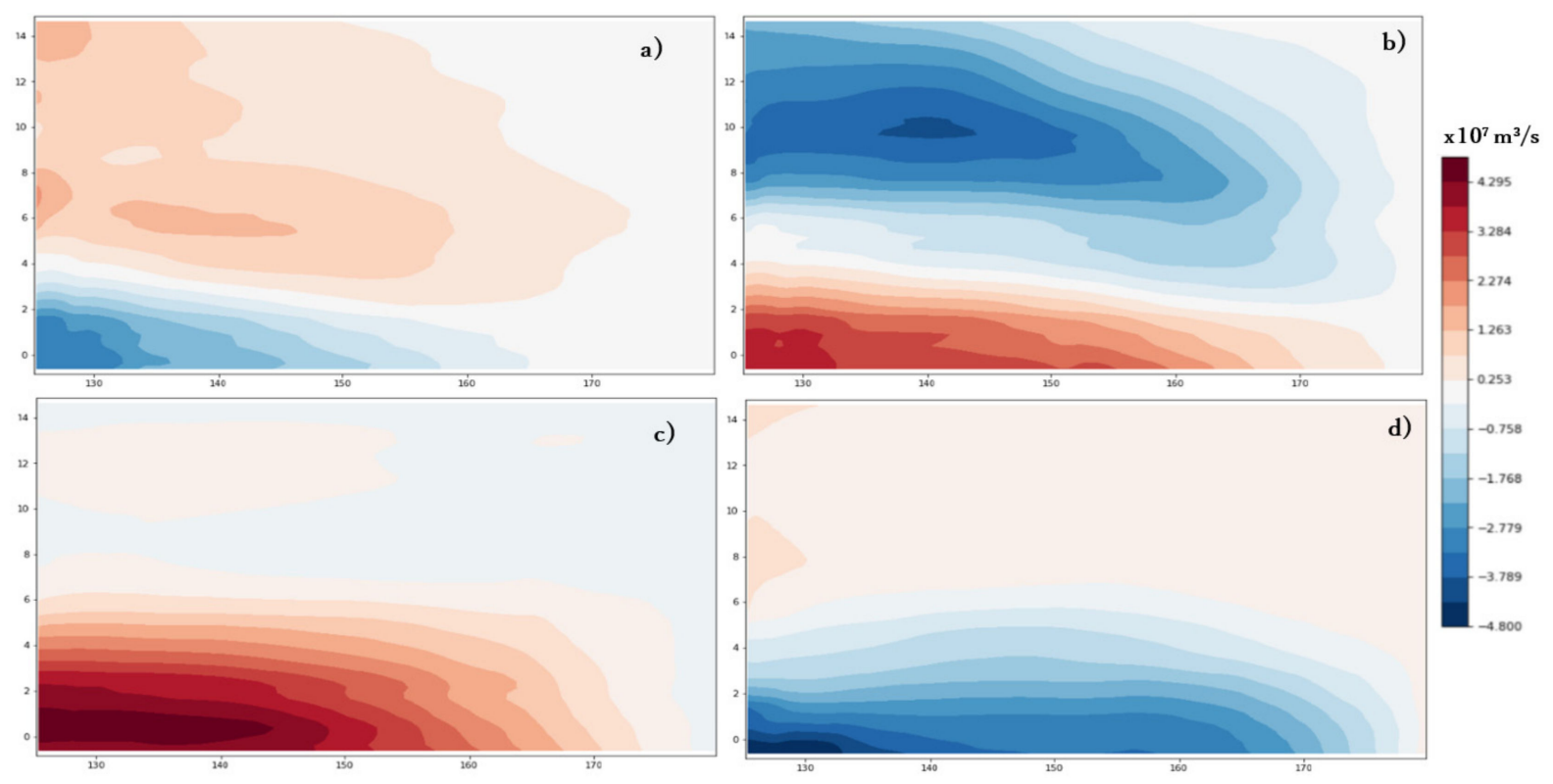

Figure 9. Zonal transport in $10^{7} \mathrm{~m}^{3} / \mathrm{s}$ for (a) the developing phase of a La Niña event, (b) the developing phase of an El Niño event, (c) the mature phase of a La Niña event, and (d) the mature phase of an El Niño event. Red and blue colors denote eastward and westward transport, respectively.

\subsection{Surrounding Sea Surface Height Anomaly (SSHA)}

The upper panels of Figure 10 present an average map of the surrounding sea surface height anomalies (SSHAs). During an El Niño or La Niña event, a positive or negative SSHA area was found, respectively, east of Mindanao Island, commonly referred to as the Mindanao Dome (MD) region. In contrast, negative or positive SSHAs were present in the equatorial region to the east of $165^{\circ} \mathrm{E}$ for an El Niño or La Niña event, respectively. These results are consistent with a prior study that found that SSHAs are lower and higher than average during El Niño and La Niña events, respectively [37]. The average geostrophic surface current is shown in the lower panel of Figure 10. The weaker NECC moved north of $\sim 6^{\circ} \mathrm{N}$ in a La Niña event, while in an El Niño event, a stronger NECC was situated further south of $\sim 1^{\circ} \mathrm{N}$. 

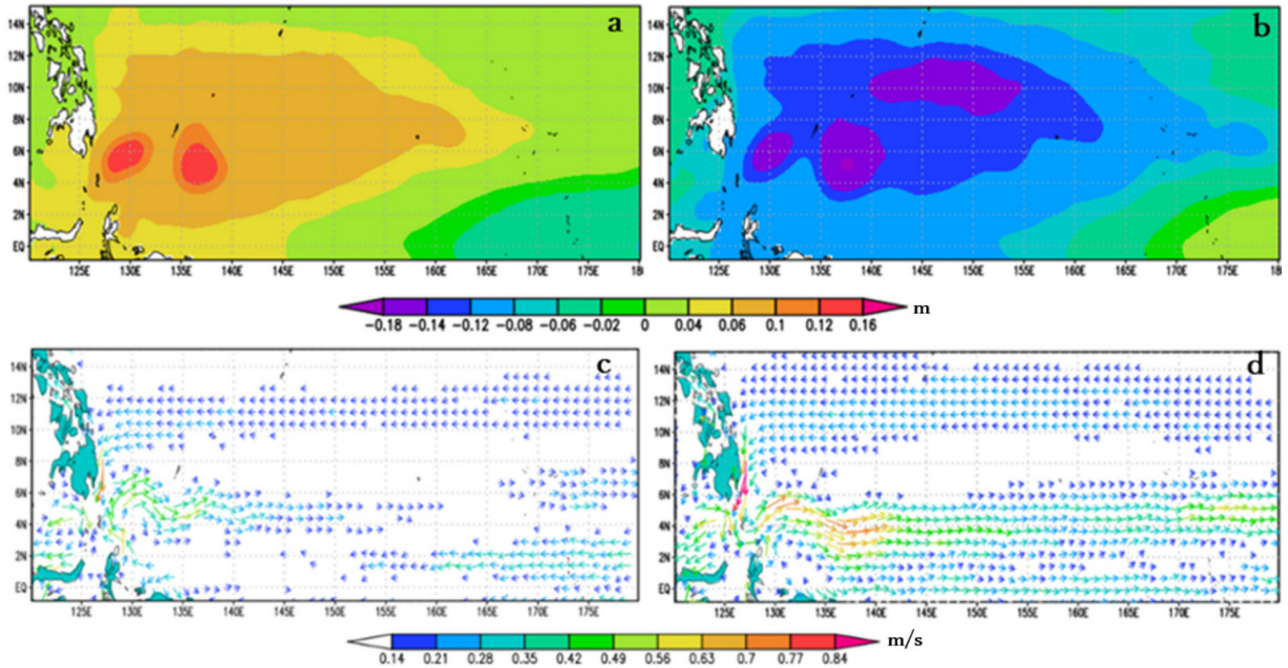

Figure 10. Average maps of the sea surface height anomalies (SSHAs) (m) during La Niña events (a) and El Niño events (b), and average maps of the geostrophic current (m/s) for La Niña events (c) and El Niño events $(\mathbf{d})$.

Oceanic wave dynamics is one phenomenon that has an important role in the circulation of the equatorial Pacific Ocean, as stated by Yuan and Han [38]. Therefore, to investigate the oceanographic conditions that induce the NECC variations, we plotted time series data of SSHAs at latitude $7^{\circ} \mathrm{N}$ in a Rossby wave investigation (shading in colors, Figure 11) and equatorially for Kelvin wave observations (black contour, Figure 11). We plotted only negative SSHAs at the equator for convenience. We divided the analysis into two periods, namely, 1993-2002 and 2008-2017. To facilitate the observation, we did not include the 2003-2007 period due to the absence of a strong El Niño event. We observed that most of the strengthening of the NECC coincided with the arrival of a negative SSHA propagating (an upwelling Rossby wave) along the $7^{\circ} \mathrm{N}$ latitude from the Eastern Pacific Ocean (Figure 11). In the El Niño events of 1997/1998 and 2015/2016, the upwelling Rossby wave appeared in the Western Pacific Ocean during the summer. While the appearance of an upwelling Rossby wave in the 2009/2010 event was captured during the fall, resulting in a difference in the timing of the developing phase with other ENSO events. This result may be why the 2009/2010 El Niño event resulted in a neutral phase (upper panel of Figure $4 \mathrm{~b}$ ). In the Western Pacific Ocean, an equatorial Kelvin wave appeared to be the result of a reflection of the Rossby wave, which propagated toward the Eastern Pacific and caused a subsequent ENSO event. The NECC variations were stronger and weaker during the developing phases of each El Niño or La Niña event, respectively, and subsequently, in the mature phase, they underwent weakening or strengthening for El Niño or La Niña events, respectively. 


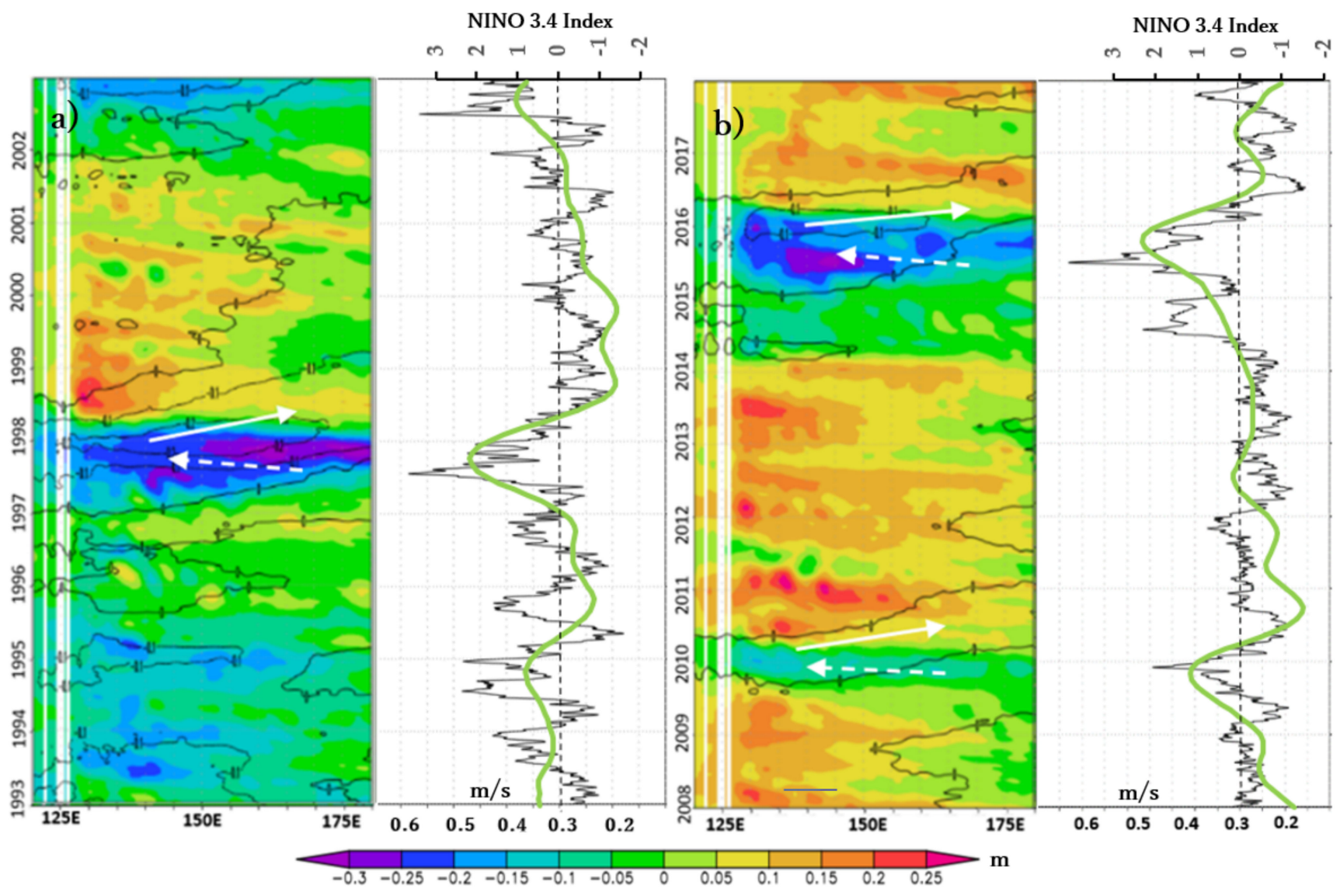

Figure 11. Left panel: 60 days of low-pass filtered of SSHA data $(\mathrm{m})$ at $7^{\circ} \mathrm{N}$ in colors, superimposed with SSHA data at $0^{\circ}$ in contour lines (only for negative values) in the Western Pacific Ocean between $120^{\circ} \mathrm{E}$ and $180^{\circ}$ E. Right panel: The average NECC (m/s) in the Western Pacific Ocean superimposed with three months of low-pass filtered Niño 3.4 index data (a) for January 1993 to December 2002 and (b) for January 2008 to December 2017. The straight and dashed arrows indicate the Kelvin and Rossby wave directions, respectively.

\section{Discussion and Conclusions}

The present paper examined the NECC variations, calculating the first three EOFs in boreal summer and winter that we considered the start of the developing and mature phases of an ENSO event, respectively, to find the dominant modes of those seasons. Because the NECC is an important flow for North Pacific Ocean gyres, which have a vital role in the climate system and are related to ENSO events, this study sought to under-stand the impact of an ENSO event on the NECC. We used surface geostrophic current data, SSH data from the CMEMS, wind data from the CCMP, and SST data from NOAA.

We found that the NECC in the Western Pacific Ocean produced a different response to El Niño and La Niña events. From the EOF analysis for the boreal summer or developing phase for El Niño or La Niña events, respectively, the first mode accounted for $36.1 \%$ of the variance, and time series variation indicated the strengthening or weakening of the NECC in each El Niño or La Niña event, respectively, in good accordance with previous findings $[7,10,12]$. Our analysis indicated a strengthening of the NECC in every El Niño event, unless there was an exception, like in the 2009/2010 El Niño event, in which the NECC appeared as a neutral phase during boreal summer in the first mode, perhaps because of the late arrival of the westward propagation of negative SSHAs (upwelling Rossby wave) from the Eastern Pacific. For the boreal winter (the mature phase), the first mode explained $26.3 \%$ of the variance. The time series analysis showed a strong relationship between the NECC and an ENSO event, as in boreal summer, suggesting that the magnitude of the NECC was above and below the average during El Niño and La Niña 
events, respectively. Although, during an El Niño event, there was a significant decrease in the NECC magnitude from the boreal summer to winter. The first mode of the boreal summer and winter analysis implied that the NECC underwent weakening throughout 2008-2017; this result is consistent with [5], where a weakening of the NECC over the last five decades was identified.

In terms of the NECCs positional shifting, we found that the NECC shifted northward and southward during La Niña and El Niño events, respectively, and that the NECC shifted during the developing and mature phases of ENSO events. For La Niña and El Niño events, the NECC shifted northward or southward and away or toward the equator in the developing phase, respectively. When entering the mature phase, the NECC shifted southward or northward in La Niña and El Niño events, respectively.

A question has arisen, "Is it possible that the NECC variations cause ENSO events?", which was addressed in Figure 6. NECC's role during the strong El Niño event has been reported by Webb [6], in which NECC played an important role in eastward movement of warm water, accompanied by a weakening of South Equatorial Current [39]. It should be noted that this only happened when El Niño event was strong. However, the ENSO event mechanism is more complex than it seems. There were other phenomena that influenced both ENSO and NECC, such as wind pattern and oceanic wave dynamics [6,7,40-42]. The mechanism of NECC variation due to ENSO events was well explained by [7], which is in good agreement with our results. The suggested mechanism is as follows: El Niño or La Niña events generated upwelling or downwelling Rossby waves that were found at the developing phase to be due to strong or weak westerly winds, respectively. The events then induced a decrease or increase in SSHA in the MD region that caused the NECC to strengthen or weaken.

Author Contributions: Conceptualization, Y.J.W.; methodology, Y.J.W. and Y.H.; software, Y.J.W.; validation, Y.J.W. and Y.H.; formal analysis, Y.J.W. and Y.H.; investigation, Y.J.W. and Y.H.; resources, Y.J.W.; data curation, Y.J.W.; writing — original draft preparation, Y.J.W.; writing—review and editing, Y.J.W. and Y.H.; visualization, Y.J.W.; supervision, Y.H.; project administration, Y.H.; funding acquisition, Y.H. All authors have read and agreed to the published version of the manuscript.

Funding: This study was financially supported by a Grant-in-Aid for Scientific Research (C-2) from the Ministry of Education, Culture, Sports, Science, and Technology of Japan (20K04708).

Informed Consent Statement: Not applicable.

Data Availability Statement: The daily data of SSH and geostrophic velocity were obtained from the CMEMS, which can be downloaded from https:/ / marine.copernicus.eu/ (accessed on 20 December 2020). Daily wind dataset from CCMP and SST dataset from NOAA are freely available at http:/ /apdrc.soest.hawaii.edu/las/v6/ dataset (accessed on 20 December 2020).

Acknowledgments: The first author is a PhD student at Department of Physics and Earth Sciences, The University of The Ryukyus and supported by Japanese Ministry of Education, Culture, Sports, Science and Technology (MEXT). Comments from the anonymous reviewers were helpful in improving the manuscript.

Conflicts of Interest: The author declares no conflict of interest. 


\section{Appendix A}

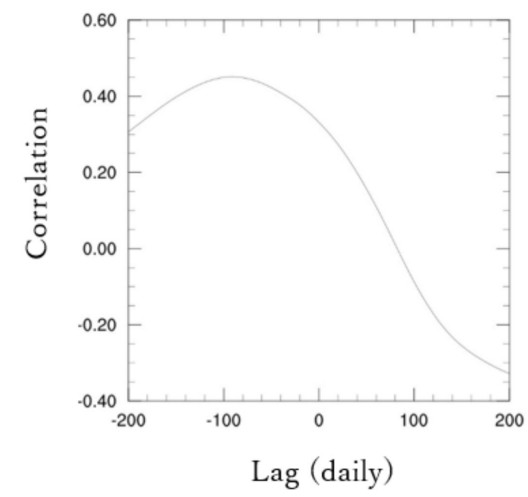

Figure A1. Lead-lag correlation between the WSC at the Niño 3.4 region and the average NECC $\left(1.125^{\circ} \mathrm{N}\right.$ to $7.125^{\circ} \mathrm{N}$ and $135.125^{\circ} \mathrm{E}$ to $\left.170.125^{\circ} \mathrm{E}\right)$. Negative lag indicates that the WSC was lagging, and positive lag indicates that the WSC was leading.

\section{References}

1. Zhao, J.; Li, Y.; Wang, F. Seasonal Variation of the Surface North Equatorial Countercurrent (NECC) in the Western Pacific Ocean. Chin. J. Oceanol. Limnol. 2016, 34, 1332-1346. [CrossRef]

2. Johnson, G.C.; Sloyan, B.M.; Kessler, W.S.; McTaggart, K.E. Direct measurements of upper ocean currents and water properties across the tropical Pacific during the 1990s. Prog. Oceanogr. 2002, 52, 31-61. [CrossRef]

3. Donguy, J.R.; Meyers, G. Mean annual variation of transport of major currents in the tropical Pacific Ocean. Deep Sea Res. Part I Oceanogr. Res. Pap. 1996, 43, 1105-1122. [CrossRef]

4. Wyrtki, K.; Kendall, R. Transports of the Pacific equatorial countercurrent. J. Geophys. Res. 1967, 72, 2073-2076. [CrossRef]

5. Chen, X.; Qiu, B.; Du, Y.; Chen, S.; Qi, Y. Interannual and interdecadal variability of the North Equatorial Countercurrent in the Western Pacific. J. Geophys. Res. Oceans 2016, 121, 7743-7758. [CrossRef]

6. Webb, D.J. On the role of the North Equatorial Counter Current during a strong El Niño. Ocean Sci. 2017, 14, 633-660. [CrossRef]

7. Zhao, J.; Li, Y.; Wang, F. Dynamical responses of the west Pacific North Equatorial Countercurrent (NECC) system to El Nino events. J. Geophys. Res. Ocean. 2013, 118, 2828-2844. [CrossRef]

8. Zhang, Q.; Liu, H.; Zhou, H.; Zheng, D. Variation Features of the Mindanao Eddy from Argo Data. Atmos. Ocean 2012, 50 (Suppl. 1), 103-115. [CrossRef]

9. Kashino, Y.; Atmadipoera, A.; Kuroda, Y.; Lukijanto, L. Observed features of the Halmahera and Mindanao Eddies. J. Geophys. Res. Ocean. 2013, 118, 6543-6560. [CrossRef]

10. Hsin, Y.-C.; Qiu, B. The impact of Eastern-Pacific versus Central-Pacific El Niños on the North Equatorial Countercurrent in the Pacific Ocean. J. Geophys. Res. 2012, 117, C11017. [CrossRef]

11. Wang, L.-C.; Wu, C.-R. Contrasting the Flow Patterns in the Equatorial Pacific between Two Types of El Niño. Atmos. Ocean 2013, 51, 60-74. [CrossRef]

12. Tan, S.; Zhou, H. The observed impacts of the two types of El Niño on the North Equatorial Countercurrent in the Pacific Ocean. Geophys. Res. Lett. 2018, 45, 10493-10500. [CrossRef]

13. Paek, H.; Yu, J.-Y.; Qian, C. Why were the 2015/2016 and 1997/1998 extreme El Niños different? Geophys. Res. Lett. 2017, 44, 1848-1856. [CrossRef]

14. Santoso, A.; Mcphaden, M.J.; Cai, W. The defining characteristics of ENSO extremes and the strong 2015/2016 El Niño. Rev. Geophys. 2017, 55, 1079-1129. [CrossRef]

15. Wen, N.; Liu, Z.; Li, L. Direct ENSO impact on East Asian summer precipitation in the developing summer. Clim. Dyn. 2018, 52, 6799-6815. [CrossRef]

16. Wu, B.; Zhou, T.; Li, T. Contrast of Rainfall-SST Relationship in the Western Pacific between the ENSO-Developing and ENSODecaying Summers. J. Clim. 2009, 22, 4398-4405. [CrossRef]

17. Park, Y.-H. Determination of the Surface Geostrophic Velocity Field from Satellite Altimetry. J. Geophys. Res. 2004, 109, C05006. [CrossRef]

18. Lagerloef, G.S.E.; Mitchum, G.T.; Lukas, R.B.; Niiler, P.P. Tropical Pacific near-surface currents estimated from altimeter, wind, and drifter data. J. Geophys. Res. 1999, 104, 23313-23326. [CrossRef]

19. Sanchez-Reales, J.M.; Vigo, M.I.; Trottini, M. Ocean Surface Geostrophic Circulation Climatology and Annual Variations Inferred from Satellite Altimetry and GOCE Gravity Data. Pure Appl. Geophys. 2014, 173, 849-860. [CrossRef]

20. Suzuki, N.; Konda, M.; Kutsuwada, K.; Utsunomiya, K. Comparison of the accuracy of various global wind speed datasets obtained from satellites and reanalyses. J. Adv. Mar. Sci. Technol. Soc. 2018, 24, 31-37. [CrossRef] 
21. Atlas, R.; Hoffman, R.N.; Ardizzone, J.; Leidner, S.M.; Jusem, J.C.; Smith, D.K.; Gombos, D.A. Cross-calibrated, multiplatform ocean surface wind velocity product for meteorological and oceanographic applications. Bull. Am. Meteorol. Soc. 2011, 92, 157-174. [CrossRef]

22. Mears, C.A.; Scott, J.; Wentz, F.J.; Ricciardulli, L.; Leidner, S.M.; Hoffman, R.; Atlas, R.A. Near-Real-Time Version of the Cross-Calibrated Multiplatform (CCMP) Ocean Surface Wind Velocity Data Set. J. Geophys. Res. Ocean. 2019, 124, 6997-7010. [CrossRef]

23. Kok, P.H.; Mohd Akhir, M.F.; Tangang, F.; Husain, M.L. Spatiotemporal trends in the southwest monsoon wind-driven upwelling in the southwestern part of the South China Sea. PLoS ONE 2017, 12, e0171979. [CrossRef]

24. Kutsuwada, K. Impact of Wind/Wind-Stress Field in the North Pacific Constructed by ADEOS/NSCAT Data. J. Oceanogr. 1998, 54, 443-456. [CrossRef]

25. Kessler, W.S.; Johnson, G.C.; Moore, D.W. Sverdrup and Nonlinear Dynamics of the Pacific Equatorial Currents. J. Phys. Oceanogr. 2003, 33, 994-1008. [CrossRef]

26. Reynolds, R.W.; Smith, T.M.; Liu, C.; Chelton, D.B.; Casey, K.S.; Schlax, M.G. Daily High-Resolution-Blended Analyses for Sea Surface Temperature. J. Clim. 2007, 20, 5473-5495. [CrossRef]

27. Chen, X.; Wallace, J.M.; Tung, K.-K. Pairwise-Rotated EOFs of Global SST. J. Clim. 2017, 30, 5473-5489. [CrossRef]

28. Hannachi, A.; Jolliffe, I.T.; Stephenson, D.B. Empirical orthogonal functions and related techniques in atmospheric science: A review. Int. J. Climatol. 2007, 27, 1119-1152. [CrossRef]

29. Levitus, S.; Antonov, J.I.; Boyer, T.P.; Garcia, H.E.; Locarnini, R.A. EOF analysis of upper ocean heat content, 1956-2003. Geophys. Res. Lett. 2005, 32, L18607. [CrossRef]

30. Chelton, D.B. Effect of sampling errors in statistical estimation. Deep-Sea Res. 1983, 30, 1083-1101. [CrossRef]

31. Yu, Z.; McCreary, J.P., Jr.; Kessler, W.S.; Kelly, K.A. Influence of Equatorial Dynamics on the Pacific North Equatorial Countercurrent. J. Phys. Oceanogr. 2000, 30, 3179-3190. [CrossRef]

32. Sun, Z.; Liu, H.; Lin, P.; Tseng, Y.-H.; Small, J.; Bryan, F. The modeling of the North Equatorial Countercurrent in the Community Earth System Model and its oceanic component. J. Adv. Model. Earth Syst. 2019, 11, 531-544. [CrossRef]

33. Tan, X.; Tang, Y.; Lian, T.; Yao, Z.; Li, X.; Chen, D. A study of the effects of westerly wind bursts on ENSO based on CESM. Clim. Dyn. 2020, 54, 885-899. [CrossRef]

34. McPhaden, M.J. Evolution of the 2002/2003 El Niño. Bull. Am. Meteorol. Soc. 1999, 85, 677-695. [CrossRef]

35. Kodama, K.; Burls, N.J.; Trenary, L. The Nino 3.4 Prediction Skill of Empirically Adjusted Wind Power. J. Clim. 2021, 34, 2001-2015. [CrossRef]

36. McPhaden, M.J.; Bahr, F.; Du Penhoat, Y.; Firing, E.; Hayes, S.P.; Niiler, P.P.; Richardson, P.L.; Toole, J.M. The Response of the Western Pacific Ocean to Westerly Wind Burst during November 1989 to January 1990. J. Geophys. Res. 1992, 97, 14289-14303. [CrossRef]

37. Lee, T.; McPhaden, M.J. Decadal phase change in largescale sea level and winds in the Indo-Pacific region at the end of the 20th century. Geophys. Res. Lett. 2008, 35, L01605. [CrossRef]

38. Yuan, D.; Han, W. Roles of Equatorial Waves and Western Boundary Reflection in the Seasonal Circulation of the Equatorial Indian Ocean. J. Phys. Oceanogr. 2005, 36, 930-944. [CrossRef]

39. Wang, J.; Lu, Y.; Wang, F.; Zhang, R.-H. Surface Current in "Hotspot" Serves as a New and Effective Precursor for El Niño Prediction. Sci. Rep. 2017, 7, 166. [CrossRef]

40. Wang, Y.; Gozolchiani, A.; Ashkenazy, Y.; Havlin, S. Oceanic El-Niño wave dynamics and climate networks. New J. Phys. 2016, 18, 033021. [CrossRef]

41. Abe, H.; Tanimoto, Y.; Hasegawa, T.; Ebuchi, N. Oceanic Rossby Waves over Eastern Tropical Pacific of Both Hemispheres Forced by Anomalous Surface Winds after Mature Phase of ENSO. J. Phys. Oceanogr. 2016, 3397-3414. [CrossRef]

42. Wang, J.; Yuan, D.; Xu, T.; Zhao, X. Wind-forced equatorial wave dynamics of the Pacific Ocean during 2014/2015 and 2015/2016 El Niño events. J. Oceanol. Limnol. 2020, 4, 1123-1137. [CrossRef] 